\title{
A Case of Neurosarcoidosis Initially Diagnosed as Multiple Sclerosis
}

\author{
Pauline Kosalka, MD, Hon. BA and Ayman Hassan, MD, FAAN
}

\author{
About the Authors \\ Pauline Kosalka is a third-year Internal Medicine resident at the Northern Ontario School of Medicine's Thunder Bay campus. \\ Ayman Hassan is an Associate professor at the Northern Ontario School of Medicine, Clinical Science Division, Department of \\ Internal Medicine, Neurology. \\ Corresponding author: pkosalka@nosm.ca \\ Submitted: March 10, 2019. Accepted: March 21, 2019. Published: February 28, 2020. DOI: 10.22374/cjgim.v15i1.358
}

\begin{abstract}
Neurosarcoidosis is an inflammatory disorder characterized by noncaseating granulomas of the central nervous system. Due to its rarity and nonspecific presentation, the diagnosis may initially be confused with other neurologic disorders such as multiple sclerosis (MS). We present a case of a 44-year-old Caucasian woman in Thunder Bay initially diagnosed with MS who developed atypical imaging findings of expanding bilateral mesial temporal lesions on magnetic resonance imaging. Brain biopsy followed by axillary lymph node biopsy established a diagnosis of neurosarcoidosis.

\section{Resume}

La neurosarcoïdose est un trouble inflammatoire caractérisé par des granulomes non caséinants du système nerveux central. En raison de sa rareté et de sa présentation non spécifique, le diagnostic peut être initialement confondu avec d'autres troubles neurologiques tels que la sclérose en plaques (SEP). Nous présentons le cas d'une femme caucasienne de 44 ans, à Thunder Bay, chez qui la sclérose en plaques a été diagnostiquée initialement et qui a développé des résultats d'imagerie atypiques de lésions temporelles mésiales bilatérales en expansion sur l'imagerie par résonance magnétique. Une biopsie du cerveau suivie d'une biopsie des ganglions lymphatiques axillaires a permis d'établir un diagnostic de neurosarcoïdose.
\end{abstract}

A 44-year-old Caucasian woman was referred to the Multiple Sclerosis clinic in Thunder Bay for relapsing-remitting multiple sclerosis (MS). She demonstrated left arm and leg ataxia, decreased right facial sensation, and diminished right leg pinprick sensation. She also had difficulties with tandem gait and falling to the left with the Romberg manoeuvre. Magnetic resonance imaging (MRI) imaging showed hyperintense lesions on T2-weighted and FLAIR MRI suggestive of demyelination.
Follow-up imaging showed the development and growth of bilateral hippocampal lesions, up to $9 \mathrm{~mm}$ in diameter on the right and $7 \mathrm{~mm}$ on the left (Figure 1).

After review of the imaging with a neuroradiologist, it was determined that the patient's findings were not consistent with MS. She was referred to neurosurgery and opted for an image-guided brain biopsy of the right-sided lesion for definitive diagnosis. The pathology revealed non-necrotizing granulomatous inflammation 


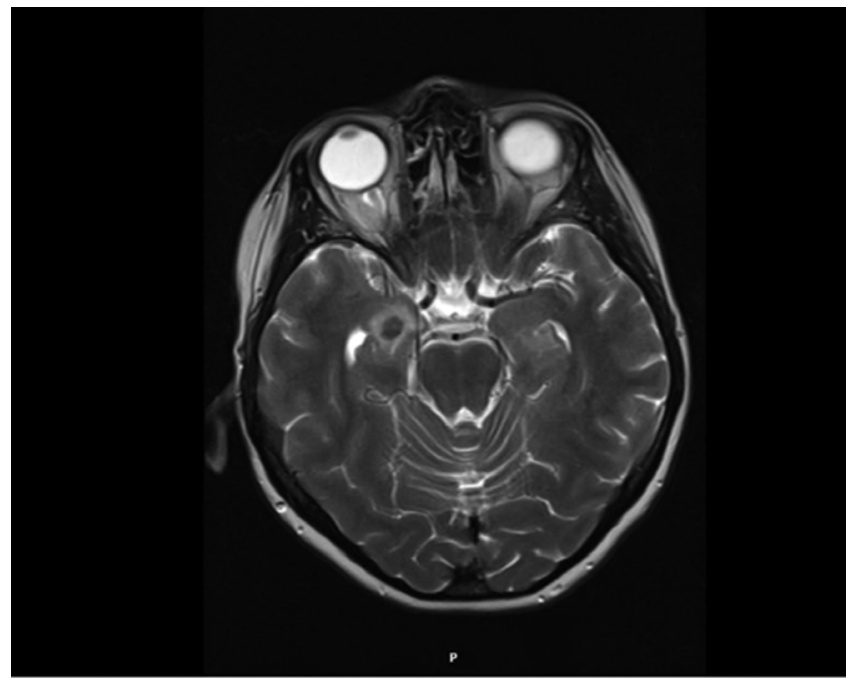

Figure 1.T2-weighted magnetic resonance imaging with gadolinium contrast showing right temporal lobe lesion with central T2 hypointensity.

most likely consistent with neurosarcoidosis. A later biopsy of a right enlarged axillary lymph node revealed similar findings.

Follow-up MRI 7 months after surgery showed a progression of intracranial disease, along with new areas of meningeal and dural enhancement (Figure 2). She was treated with high-dose glucocorticoids followed by infliximab for her neurosarcoidosis. Topiramate was also started after she developed seizures secondary to her structural brain abnormalities.

Sarcoidosis is a multisystem inflammatory disorder associated with noncaseating granulomas composed of macrophages, multinucleated giant cells, and epithelioid cells surrounded by a rim of CD4 positive T-cells. Neurosarcoidosis refers to granulomatous involvement of the nervous system. Neurosarcoidosis may present with cranial nerve palsies, neuroendocrine dysfunction, seizures, cognitive or behavioural changes, stroke, radiculopathy, hydrocephalus, aseptic meningitis, peripheral neuropathy, ataxia, headache, memory loss, fatigue, and weakness. MRI findings include optic neuritis, T2-weighted hyperintensity, leptomeningeal thickening and enhancement, mass lesions, and spinal cord involvement. ${ }^{1,2}$

Neurosarcoidosis is a pathological diagnosis as well as a diagnosis of exclusion. According to the modified Zajicek's criteria, the diagnosis is "definite" if neurologic tissue demonstrated findings of sarcoidosis, "probable" if pathology shows sarcoidosis is in an extraneural site and the patient has neurologic manifestations, and "possible" in the presence of characteristic neurologic involvement without tissue diagnosis. ${ }^{3}$

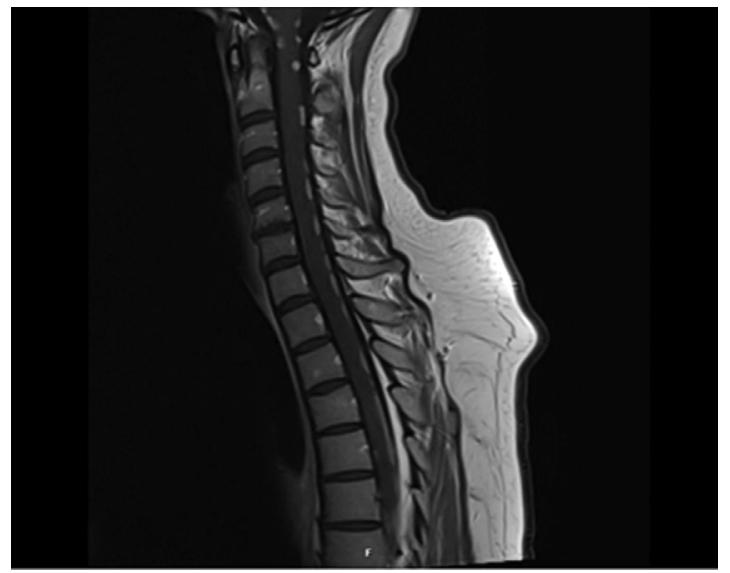

Figure 2. Magnetic resonance imaging of the spine with gadolinium contrast 7 months after surgery showing multiple segments of abnormal nodular enhancement of meninges.

Corticosteroids are the initial treatment for neurosarcoidosis. The disease often recurs after steroid discontinuation or becomes steroid-resistant, at which point immunosuppressants and biologics may be considered.

\section{Funding Statement}

There are no sources of funding for this project.

\section{Acknowledgement}

The authors wish to acknowledge Dr. Donald Lee (radiologist, London Health Sciences Centre University Hospital) for his assistance in the interpretation of the neuroimaging and drafting of the manuscript.

\section{Competing Interests}

None.

\section{References}

1. Tavee JO, Stern BJ. Neurosarcoidosis. Clin Chest Med 2015;36:643-56. Available at: https://www.sciencedirect.com/science/article/pii/ S0272523115001070?via\%3Dihub

2. Visee H, Duprez TP, Sindic CJM. Diagnostic and therapeutic pitfalls in neurosarcoidosis. Acta Neurol Belg 2009;109:91-99. Available at: https:// www.ncbi.nlm.nih.gov/pubmed/?term $=$ Visee $+\mathrm{H} \% 2 \mathrm{C}+$ Duprez+TP\%2C + Sindic+CJM.+Diagnostic+and+therapeutic+pitfalls+in+neurosarcoidosis

3. Owen CI, Jabeen F, Bhattacharjee A. Application of the modified Zajicek criteria to diagnose probable spinal cord neurosarcoidosis. Clin Case Rep 2018;6:1718-22. Available at: https:/www.ncbi.nlm.nih.gov/pmc/articles/ PMC6132158/ 